\title{
Role of Contrast-Enhanced Ultrasound (CEUS) in Paediatric Practice: An EFSUMB Position Statement
}

Authors

Paul S. Sidhu ${ }^{1}$, Vito Cantisani², Annamaria Deganello ${ }^{1}$,

Christoph F. Dietrich ${ }^{3}$, Carmina Duran ${ }^{4}$, Doris Franke ${ }^{5}$,

Zoltan Harkanyi ${ }^{6}$, Wojciech Kosiak ${ }^{7}$, Vittorio Miele ${ }^{8}$, Aikaterini Ntoulia ${ }^{1}$,

Maciej Piskunowicz ${ }^{9}$, Maria E. Sellars ${ }^{1}$, Odd Helge Gilja ${ }^{10}$

Affiliations

1 Department of Radiology, King's College Hospital, London, United Kingdom.

2 Department of Radiological Sciences, Oncology and Pathology, Policlinico Umberto I, University Sapienza, Rome, Italy.

3 Department of Internal Medicine 2, Caritas Krankenhaus, Bad Mergentheim, Bad Mergentheim, Germany.

4 Department of Radiology, Parc Tauli University Hospital, Sabadell, Spain.

5 Pediatric Sonography, Department of Pediatric Kidney, Liver and Metabolic Diseases, Children's Hospital, Hannover Medical School, Hannover, Germany

6 Department of Radiology, Heim Pal Children's' Hospital, Budapest, Hungary

7 Department of Pediatrics, Hematology and Oncology, Medical University of Gdansk, Gdansk, Poland

8 Department of Emergency Radiology, S. Camillo Hospital, Rome, Italy

9 Department of Radiology, Medical University of Gdansk, Gdansk, Poland

10 National Centre for Ultrasound in Gastronterology, Haukeland University Hospital, Bergen and Department of Clinical Medicine, University of Bergen, Norway.

Key words

microbubbles, CEUS, paediatric received 15.5.2016

accepted 6.6.2016

Bibliography

DOI http://dx.doi.org/10.1055/s-0042-110394

Published online: July 14, 2016 | Ultraschall in Med 2017; 38: 33-43

(c) Georg Thieme Verlag KG Stuttgart · New York

ISSN 0172-4614

Correspondence

Dr. Paul S. Sidhu

Radiology, King's College London, King's College Hospital

Denmark Hill

SE5 9RS London

United Kingdom of Great Britain and Northern Ireland

Tel.: ++/44/2 03/2994164

Fax: ++ 44/2 03/299157

paulsidhu@nhs.net

\section{ABSTRACT}

The use of contrast-enhanced ultrasound (CEUS) in adults is well established in many different areas, with a number of current applications deemed "off-label", but the use supported by clinical experience and evidence. Paediatric CEUS is also an "off-label” application until recently with approval specifically for assessment of focal liver lesions. Nevertheless there is mounting evidence of the usefulness of CEUS in children in many areas, primarily as an imaging technique that reduces exposure to radiation, iodinated contrast medium and the "patientfriendly" circumstances of ultrasonography. This position statement of the European Federation of Societies in Ultrasound and Medicine (EFSUMB) assesses the current status of CEUS applications in children and makes suggestions for further development of this technique.

\section{Introduction}

Ultrasound (US) has long been established as the ideal first imaging examination in children, with excellent diagnostic capabilities in the investigation of diverse body parts such as the abdomen, the neonatal brain or the pleural cavity. Nevertheless, inherent limitations and the frequently inconclusive nature of B-mode US may require further cross-sectional imaging including Computed Tomography (CT) or Magnetic Resonance (MR) imaging in order to increase diagnostic certainty. These investigations require contrast administration, inevitably in $\mathrm{CT}$ and frequently in MR imaging. Contrast agents in CT and MR imaging are associated with increased risks both in the adult and child, with gadolinium agents facing greater scrutiny as to long term adverse effects, pertinent to the child [1]. A further "hazard" with the child entailed in CT and more often in MR imaging is the need to render the child immobile throughout the examination either with conscious sedation or general anaesthesia. However the need to reduce radiation exposure in the child is the over-riding aim of every imaging work-up algorithm; cancer risk from medical exposure is not a trivial issue [2-4]. Any adjuvant to the baseline US investigation that can obviate the need for further CT or MR imaging in the child would be valuable.

Contrast-enhanced ultrasound (CEUS) with the currently commercially available second generation US contrast agents (UCA) has become a standard imaging option in adult clinical practice for a number of years with an exceptionally high safety profile [5]. Adult CEUS practice across many body organs is established with detailed guidelines on the application published [6, 7]. Many of the applications are "off-label" but the justification for this is often supported by clinical evidence of the usefulness of CEUS [8, 9]. The extension of CEUS into paediatric clinical practice has been slow to develop, mainly hampered by the lack of a "licence" and clinical experience; neither an unsurmountable issue. The use of "off-label" drugs in paediatric practice is well known [10-12] and the justification for "off-label" use is sanc- 
tioned by the medical regulatory authorities [13]. Previously the only licence for the use of CEUS in paediatric practice was for vesico-ureteric reflux using an agent not currently marketed [14]. There is increasing evidence for the safe intravenous use of UCA in children [15-17]. Diagnostically efficient investigations using intravenous CEUS in children are increasingly reported [18-21].

Among the currently available second generation UCA, two have been already used in children; SonoVue ${ }^{\mathrm{TM}}$ (Bracco SpA, Milan) containing sulphur hexafluoride gas microbubbles and Optison $^{\mathrm{TM}}$ (GE Healthcare Inc., Princeton, NJ) containing perflutren gas microbubbles. Recently the Food and Drug Administration (FDA) in the United States of America has authorized the use of SonoVue ${ }^{\mathrm{TM}}$ under the commercial name Lumason ${ }^{\mathrm{TM}}$ for liver applications in paediatric patients, which is likely to have a profound effect on paediatric US imaging worldwide [22, 23]. This position statement of the European Federation of Societies in Ultrasound and Medicine (EFSUMB) assesses the current status of CEUS applications in children and makes suggestions for further development of this technique.

\section{General Considerations}

The issue of consent for the CEUS examination is complex. In most cases the administration of the UCA is "off-label", and written consent for UCA administration may be a hospital requirement. The consent should be obtained from parents or legal guardians prior to examination. However, local policies may vary and informed verbal consent is all that may be required. Some hospital authorities require written consent for all contrast examinations, and administration of an UCA should also be included in this requirement.

The standard manufacturer's list of contraindications needs to be observed. Contraindications include a history of known hypersensitivity to the active substance or excipients, children with right-to-left shunts, severe pulmonary hypertension, uncontrolled systemic hypertension, and uncertain pregnancy status where applicable.

As with all contrast administration, ready access to resuscitation equipment is mandatory and should be in close proximity to the room where CEUS examinations are conducted. All personnel involved with UCA administration in children should have basic skills in identifying and treating a contrast reaction in a child.

\section{Paediatric CEUS Safety Considerations}

Safety regarding the intra-venous use of UCA in the children is principally focused on the "off-label" usage. Despite the variability in the legislation between different countries, the "off-label" use of pharmaceutical products in children is a relatively common phenomenon; $11-37 \%$ of outpatient treated children, $16-62 \%$ of in-patient treated children and $51-80 \%$ of neonatal patients may have received "off-label" medications [10 - 12]. The "offlabel" use of a pharmaceutical product may be considered appropriate in cases where the benefits of its use outweigh the potential risks of non-treatment. In this context, paediatric CEUS has the potential to influence or even change the diagnostic and therapeutic decisions.
The safety profile of UCA during intravenous administration has been documented in a large cohort of 23188 adults with the second generation UCA SonoVue/Lumason ${ }^{\mathrm{TM}}$ (Bracco SpA, Milan), with no fatal event encountered and only 29 (3 severe, 3 moderate and 23 mild) adverse reactions noted [5]. The overall rate of adverse events $(0.0086 \%)$ was comparable to the administration of contrast media used in MR imaging (0.0088\%) [24] and considerably lower than iodinated contrast media used in CT imaging (0.6\%) [25].

The safety profile of UCA in children is based on limited information; there are only three dedicated safety studies which have included vital signs monitoring, all using perflutren containing UCA [17, 20, 26]. In a study of 13 children who underwent intravenous CEUS with escalating doses of UCA based on the body surface, three children experienced mild adverse events; two had altered taste and one mild tinnitus and light-headedness [20]. In a further study by the same group, 134 CEUS examinations in 34 children (median age 8.7 years) were evaluated, reporting a similar frequency and nature of adverse reactions [17]. In a study of 20 children (median age 15 years) four experienced adverse reactions, three children developed transient headache and one reported brief alteration of taste sensation [26].

A sulphur hexafluoride gas containing UCA was also evaluated in a dedicated safety evaluation study of 161 intravenous CEUS investigations in 137 children (median 10.2 years) [21]. In a single case $(0.6 \%)$, severe anaphylactoid shock, potentially life threatening and directly related to the intravenous UCA administration was encountered. Observed symptoms were generalized pruritus, nausea, and hypotension with tachycardia initially then bradycardia. Management consisted of oxygen, intravenous epinephrine and fluids ( $0.9 \%$ normal saline) with resolution in two hours. In 37 children who underwent intravenous CEUS, an 8-year-old girl reported nausea 15 minutes after UCA administration, which continued for 30 minutes [27]. In addition, a retrospective survey analysis of 948 examinations (29 European centres) all performed with SonoVue ${ }^{\mathrm{TM}} /$ Lumason $^{\mathrm{TM}}$, five minor adverse events were recorded; skin reaction, unusual taste and hyperventilation were observed [28].

More extensive safety data has been recorded with intra-vesical administration of UCA during contrast-enhanced voiding urosonography (ceVUS) in a total of 13 studies encompassing 2087 children [29-42]. In the majority of these studies safety data was acquired from the time of the examination and up to 48 hours following the examination. No serious adverse events were encountered, with only $3.7 \%$ of children reporting minor adverse events in one safety-dedicated study, which included symptoms of dysuria, abdominal pain, blood and mucous discharge, perineal irritation and urinary tract infection [35]. Symptoms such as anxiety and crying over micturition were also encountered and were likely attributed to the procedural technique rather than the UCA administration, as similar events are reported with other imaging examinations entailing bladder catheterization. Furthermore, Included in the retrospective survey analysis among 29 European centres, 4131 children underwent ceVUS with only minor dysuria symptoms reported [28].

No study has evaluated the in-vivo interaction between UCA and bladder urothelium. A few experimental studies have shown 
that in the presence of gas-filled microbubbles, the interaction of tissues and US waves may result in decrease of tissue cavitation threshold and possible disruption of cellular membranes resulting in haemolytic events. However, this phenomenon, which is frequency dependent, has been described in-vitro, with US frequencies that are above the diagnostic medical range [43].

\section{Position Comment}

The evidence to date suggests than the safety profile of UCA in adults is good, and comparable to contrast agents used in MR imaging, better than the contrast agents in CT imaging. The more limited safety data in children suggests that UCA are as safe in children as in the adult population.

\section{Current Applications}

\section{Focal Liver Lesions}

\section{Background}

The evaluation of focal liver lesions (FLL) that are detected during baseline US in underlying normal or diseased livers is an important application for CEUS in children. Similarly to that established in adults, there is the potential in paediatric diagnostic practice for CEUS to have a higher diagnostic accuracy in the evaluation of a FLL compared to grey scale US supplemented by colour Doppler techniques and perhaps with comparable accuracy to contrastenhanced CT and MR imaging. This could potentially include Focal Nodular Hyperplasia (FNH) with typical and diagnostic appearances on CEUS but non-specific B-mode US features, obviating the need for further cross-sectional imaging. Other commonly reported benign FLL that could be accurately characterized by CEUS in children are haemangiomas, hepatocellular adenomas, hepatic cysts, abscesses, regenerative nodules and focal areas of fatty sparring or infiltration. Furthermore, CEUS can provide information in identifying viable tissue within a FLL, allowing a targeted biopsy and facilitating accurate tissue sampling. Contrast-enhanced ultrasound can reveal the presence of additional lesions, not detected during preceding B-mode US.

\section{Technical Aspects}

Following intravenous administration of a single UCA dose, targeted evaluation of enhancement dynamics is performed under real-time US imaging in all vascular phases. The enhancement patterns of the FLL are similar to the well-described enhancement patterns noted in CT and MR imaging, with the hallmark of contrast "hypo-enhancement" during the portal venous phase being indicative of malignancy [6]. There are no standardized dosage schemes of the administrated UCA for paediatric CEUS. In published studies of paediatric liver CEUS with SonoVue ${ }^{\mathrm{TM}} /$ Lumason $^{\mathrm{TM}}$, the volume of a single SonoVue ${ }^{\mathrm{TM}} /$ Lumason $^{\mathrm{TM}}$ dose ranges between $0.1 \mathrm{~mL}$ to $4.8 \mathrm{~mL}$. The volume of the administered UCA is extrapolated from the licensed adult dose for liver applications and has been described to be adjusted according to child's age, body surface or body weight in the case of obese children as well as the type of US scanner, transducer and processing software used e.g. (a) $0.1 \mathrm{~mL}$ of SonoVue ${ }^{\mathrm{TM}} /$ Lumason $^{\mathrm{TM}}$ for each year of age [27] and (b) standard single dose of $0.1 \mathrm{~mL}, 0.5 \mathrm{~mL}, 1 \mathrm{~mL}$,
$1.2 \mathrm{~mL}, 2.4 \mathrm{~mL}$ or $4.8 \mathrm{~mL}$ of SonoVue ${ }^{\mathrm{TM}} /$ Lumason $^{\mathrm{TM}}$ [44 - 47]. The recommendation of the FDA for the dose of SonoVue ${ }^{\mathrm{TM}} /$ Lumason $^{\mathrm{TM}}$ in children is based on body weight; $0.03 \mathrm{~mL} / \mathrm{kg}$ as an intravenous injection, up to a maximum of $2.4 \mathrm{~mL}$ per injection [23]. Overall, it is accepted that the dose of the administrated UCA may be reduced in children. Moreover, the timing of the liver vascular phases is different in children compared to adults and significantly varies depending on the child's age [48]. It should be noted that arterial phase imaging of liver in infants might begin approximately 5 - 6 seconds following intravenous administration of microbubbles and the site (peripheral or central) of intravenous access has further influence [49].

\section{Level of Evidence}

There is accumulating evidence regarding the intravenous applications of UCA for the characterization of FLL in children. This experience stems from limited cohort studies and case reports encompassing exclusively paediatric patients as well as from larger studies entailing mixed adult and paediatric patients.

In total 4 original paediatric studies including 125 children (newborn to 18 years old) have been conducted for evaluation of FLL $[21,27,45,46]$. The largest series of FLL evaluated with CEUS to date described 44 children (median age 11.5 years) evaluated for the characterization of FLL detected during B-mode US imaging [45]. In all cases CT imaging was used as a reference examination and in some cases MR/ PET CT/histology results were also available. This study included primarily benign FLL and demonstrated $98 \%$ specificity of CEUS in accurately confirming the benign nature of FLL based on the enhancement patterns and the absence of contrast "wash-out" during portal venous phase. Importantly, many original studies, including mixed adult and paediatric patients, have been conducted for evaluation of FLL [50 - 59]. All studies demonstrated the feasibility, safety and high diagnostic accuracy of CEUS regarding the characterization of FLL, similar to CT and MR imaging. In the European survey of paediatric CEUS, of the 948 pediatric CEUS examinations performed with intravenous UCA [28], evaluation of FLL was the most common indication. A recent review of the literature on paediatric intravenous applications of CEUS in 2015 described 540 published paediatric CEUS examinations with liver examinations the most frequent indication, $41 \%$ of these cases [16].

A further six review articles that emphasize the advantages of paediatric intravenous CEUS for the evaluation of FLL and promote the need for incorporation of CEUS into routine clinical practice have been published [15, 45, 60 - 64]

\section{Position Comment}

Characterization of FLL in children is among the most commonly reported application of paediatric intravenous CEUS. The enhancement patterns of FLL in CEUS are similar to other imaging modalities and contrast "hypo-enhancement" during portal venous phase is highly specific for malignancy. 


\section{Renal}

\section{Background}

The clinical impact of CEUS in renal disease is less well-documented than in the liver, and its ultimate role is still subject to debate, with a recent review documenting current adult practice [65]. The most frequent paediatric CEUS application of the urinary tract is ceVUS, with the intra-vesical UCA administration for the assessment of vesical-ureteric reflux (VUR). The EFSUMB guidelines have established adult indications of renal intravenous CEUS [7] with little published data available regarding paediatric indications $[66,67]$. Potential uses of intravenous CEUS in children include diagnosis and follow-up of complicated infection (abscess), cystic masses and complicated cysts, renal trauma, infarction, cortical necrosis [68], transplants, tumour vascularity, renal artery stenosis and where there is a contraindication to $\mathrm{CT}$ or MR imaging contrast agents.

\section{Technique}

With a single vascular supply to the kidney, compared to the dual supply of the liver, a smaller dose of the UCA is needed for renal opacification. After a very short period of cortical enhancement (5-10 seconds after IV bolus injection), UCA can be seen the medulla which lasts $45-120$ seconds after injection. The contrast enhancement of the cortex occurs almost immediately after the arrival of the UCA in the main renal artery, with rapid subsequent renal vein enhancement $[65,69]$. Limitations of renal CEUS are identical to all US abdominal studies in children; lack of respiratory cooperation can limit the observation during the short cortical phase and the simultaneous comparison with contralateral kidney is not possible. Furthermore, as the contrast agents are not excreted by the kidney, function and evaluation of the pelvicalyceal system is not possible.

\section{Level of Evidence}

Diagnosis of abscesses complicating pyelonephritis and response to antibiotic treatment can be documented by CEUS (a central defect with rim enhancement). Complicated renal cysts are infrequent in children but CEUS may be appropriate for renal cyst classification with the modified US Bosniak system [65], and the true nature of indeterminate masses in children may be helped using CEUS. A particular advantage of a CEUS examination is the better depiction of internal vascularity of a lesion compared to MR or CT imaging, potentially evaluating solid renal tumor vascularity prior to and during chemotherapy [67]. CEUS can be used to determine the extent of renal parenchymal injury in blunt abdominal trauma, and useful in the followup of parenchymal injuries or for the assessment of complications after the admission CT imaging $[70,71]$. Acute renal transplant rejection may potentially be diagnosed by CEUS, as well as stenosis and occlusion of the transplant renal artery in the early stages [72].

\section{Position Comment}

Renal assessment in blunt abdominal trauma is promising with evidence to indicate usefulness in follow-up. There is no data available on the assessment of focal lesions, cysts and in the assessment of renal transplants in the child; indications are likely to be similar to those in the adult with more emphasis on childhood renal lesions with attention to tumour vascularity.

\section{Abdominal Trauma}

\section{Background}

The use of paediatric CEUS in the clinical setting of blunt abdominal trauma is attractive. Other techniques that assess blunt abdominal trauma in children such as Focused Assessment with Sonography for Trauma (FAST) and CT imaging both have inherent constraints. A FAST examination is sensitive in detecting free peritoneal fluid as an indirect sign of injury but has poor sensitivity in directly revealing solid organ injury. Contrast-enhanced CT is over utilized in trauma patients, imaging unnecessarily a wide spectrum of severity, ranging from minor, single-system injuries to devastating, multi-trauma; a balance needs to be achieved in the child. As in adults, paediatric CEUS is an effective alternative or supplementary imaging option to $\mathrm{CT}$ imaging in the following situations: (a) in haemodynamically stable patients who sustained isolated, low or moderate energy blunt abdominal trauma; (b) in patients with indeterminate or normal CT findings and suspicious laboratory tests; (c) in the follow-up of traumatic injuries that are managed conservatively in order to ensure resolution of the lesions or detect any associated complications, including pseudoaneurysm formation [19, 71, 73-75]. CEUS can identify traumatic injuries and evaluate their extension with higher diagnostic accuracy compared to baseline US and comparable to CT imaging, and can detect associated complications [76].

\section{Technique}

CEUS in trauma is performed following bolus intravenous administration of two separate UCA doses. The first dose is administered to investigate organs in the right upper quadrant (kidney, adrenal gland, pancreas and liver), whereas the second is administered to evaluate organs in the left (kidney, adrenal gland and spleen). The CEUS examination should commence from the side of clinical concern. The kidney should be examined first as this will rapidly enhance, with a detailed examination throughout arterial phase, whereas the spleen, and liver are evaluated during the portal venous phases. Any traumatic lesion, laceration or contusion, will appear as a clearly demarcated hypoechoic area compared to the adjacent parenchyma. Follow-up CEUS imaging targets only the organ identified on baseline imaging, and a single dose of UCA will suffice.

\section{Level of Evidence}

There are a number of studies relating specifically to the assessment of blunt abdominal trauma in children $[19,68,71,73,75$, 77]. The largest series of children $(n=74)$ underwent comparative B-mode US, CEUS and CT [19]. The diagnostic performance of CEUS was better than B-mode US and similar to $\mathrm{CT}$ imaging. Moreover, CEUS identified prognostic factors for the clinical course of trauma patients, such as parenchymal active bleeding $(n=8)$ and partial splenic devascularization $(n=1)$. A previous study with a smaller number of children $(n=27)$, demonstrated a sensitivity and specificity for CEUS compared to CT for the detection of solid organ injuries at $92.2 \%$ and $100 \%$ respectively [73]. A 
study that evaluated the incidence of post-traumatic complications in a cohort of 17 children, demonstrating $83 \%$ sensitivity and $92 \%$ specificity of CEUS for the accurate detection of liver and splenic pseudoaneurysms [71]. A number of case reports present CEUS imaging findings in isolated pancreatic and splenic injuries, as well as a case of renal cortical necrosis [68, 71, 75]. A number of studies including a mixture of adult and paediatric patients are described in the literature, all large cohorts, demonstrating the feasibility and the high diagnostic accuracy of CEUS in the diagnostic algorithm of solid organ injuries [19, 73, 74, $76-84]$.

\section{Position Comment}

CEUS has shown to be a reliable tool in the diagnosis and follow-up of solid organs injuries in paediatric patients who sustained low to moderate energy traumatic events, with the important advantage of being a highly sensitive, radiation free and child friendly imaging technique, allowing for repeated imaging. This should form the basis of follow-up of solid organ injury to reduce radiation and the use of iodinated contrast agents.

\section{Pediatric Transplantation}

\section{Background}

Possible indications for the application of CEUS in children with transplantations (renal, liver, pancreas and renal combined), are likely similar to adult indications, and the application of CEUS to the imaging assessment is likely to be of substantial clinical relevance. Most adult investigations have focused on the liver [51, 85 - 88] pancreas [89] and kidney [90 - 95]. Assessment of a number of potential areas in the transplanted child include differentiation of incidental focal liver lesions [96], suspected post-transplant-lymphoproliferative disease (PTLD), paediatric tumour characterization before and after transplantation, depiction of vascularity, vascular patency before and after solid organ transplantation (liver [97], kidney, pancreas, bowel) or skin flaps [98], ischemic alterations such as infarction, active bleeding, graft vs. host disease (GVHD) [99] of the bowel and infectious complications after transplantation.

\section{Level of Evidence}

Nearly all studies of the use of CEUS in transplantation combine adult and paediatric patients. The identification of complications following solid organ or stem cell transplantation using CEUS can confirm the preliminary clinical diagnosis, provide additional information relevant to the therapeutic management and obviate any additional diagnostic procedure.

\section{Position Comment}

The application of CEUS in the child following transplantation is likely to be similar to the adult, with vascular patency, areas of necrosis, assessment of new focal lesions and the assessment of post-operative complications (e. g. fluid collections) most likely the areas of use.

\section{Lung and Pleural Space}

\section{Background}

Although US has been applied for the evaluation of consolidated lung and the adjacent pleural spaces in adults, the use of CEUS in children has not been comprehensively described. However, there are reports that suggest that CEUS may improve the diagnostic confidence of grey scale US supplemented by colour and power Doppler imaging in differentiating consolidated lung from cavitating pneumonia in children, and better delineating the extend and contents of associated para-pneumonic fluid collections [100107]. In addition, there is limited evidence that CEUS can evaluate the enhancement dynamics in cases of pleural-based lesions, allowing for their improved characterization [101, 106].

\section{Technique}

Following UCA administration, targeted evaluation of the lung and pleural spaces is performed in coronal plane using lateral and posterior acoustic windows, in a comparable manner to grey scale lung US. There are no standardized dosage schemes for this application in the pediatric population; however a single dose of $2.4 \mathrm{~mL}$ has been described [100].

\section{Level of Evidence}

There is one study presenting the CEUS patterns in cases of pneumonia in a population group consisted of 50 adults and children older than 17 years. In this study, evaluation of the affected lung in terms of blood supply and enhancement could be used as prognostic indicator for development of associated complications [100]. Investigation by CEUS of lung and pleural lesions in children are also described [101, 104].

\section{Position Comment}

Lung CEUS is a relatively new diagnostic method that could potentially increase the diagnostic confidence to differentiate consolidated lung from cavitating pneumonia in children. This technique may also improve the visualization of pleural fluid.

\section{Spleen}

Background

Trauma is an indication for use of CEUS of the commonly injured spleen in children, with CEUS of significantly higher sensitivity for the diagnosis of splenic laceration, rupture, fracture or active bleeding than B-mode or Doppler US [19, 71, 74, 75, 108]. This has the potential to reduce the radiation exposure [109] with follow-up imaging performed with targeted CEUS of the spleen once baseline imaging (either CT or US as the situation decrees) confirms the site and extent of injury [7, 71]. Splenic diffuse or focal pathology is difficult to characterize and differentiate on any imaging modality. Suitable indications in children are the differential diagnoses of splenic focal lesions (e. g. lymphoma, haemangioma [110], complex cyst and abscess) and vascular alterations such as splenic infarction, aneurysms and quantification of viable parenchyma in hyposplenia in sickle-cell disease [67]. In children, the percentage of inborn focal splenic lesions such as hamartoma 
or lymphangioma and the range of differential diagnoses due to metabolic diseases might be higher compared to adults.

\section{Technique}

The intravenous administration of US contrast will mirror the doses in adults; usually a smaller dose (typically $1.2 \mathrm{mLs}$ SonoVue ${ }^{\mathrm{TM}}$ / Lumason $^{\mathrm{TM}}$ in adults) will suffice in the child. Careful consideration of the unique vascularization pattern of the spleen to avoid misinterpretation of abnormalities must be observed [7]. Typically, evaluation of the splenic parenchyma is performed during venous and delayed phases.

\section{Level of Evidence}

Evidence for splenic pathology, apart from trauma, is sparse. There is strong evidence for the application of CEUS in splenic trauma.

\section{Position Comment}

Diagnosis and follow-up of splenic trauma in children is an ideal application of CEUS.

\section{Adrenals}

The value of conventional US in the detection of adrenal gland tumours is well known; lesions $>10 \mathrm{~mm}$ are detectable, but characterisation is more difficult. The differentiation of benign and malignant adrenal gland tumours is not possible using CEUS [111 - 113]. No data regarding the use of CEUS in children for further characterization of adrenal gland tumours is available. Isolated case reports documenting adrenal lesions in children are available $[114,115]$. Evaluation of trauma to the adrenal gland and differentiation of haematoma from underling adrenal gland tumour may be helpful [77]. Future perspectives of CEUS include evaluation of haemorrhage in neonates.

\section{Position Comment}

Adrenal CEUS could be used in trauma or haematoma of the adrenal, evaluating resolution in place of CT.

\section{Inflammatory bowel disease}

\section{Background}

The diagnosis of inflammatory bowel disease (IBD) in children and the classification of Crohn's disease (CD) or ulcerative colitis (UC) is achieved with the combination of endoscopy, biopsy, laboratory markers and imaging work-up. Though CT Enterography (CTE) and MR Enterography (MRE) are the diagnostic examinations of choice for IBD in children, the role of CEUS is increasing. Similarly to adults, paediatric CEUS has proved to determine accurately the extent of the disease, differentiate between actively inflamed bowel and chronic fibrotic strictures, evaluate the response to treatment, and identify the presence of associated mural and extramural pathology. In addition, post-processing quantitative evaluation of the visualized bowel wall enhancement through assessment of time-intensity curves allows for objective and reproducible evaluation of the degree of bowel wall enhancement.

\section{Technique}

A fasting period of 6 hours is required. Initially, an unenhanced US examination is performed supplemented by colour and power Doppler US to identify the pathologically thickened loop of small bowel. Following intravenous UCA administration, the involved intestinal segment is targeted for CEUS evaluation of the degree of bowel wall enhancement. There is no standardized dosage scheme for CEUS performance in IBD. The most commonly used schemes are associated with the frequency of the used transducer and are the following: (a) $1.2 \mathrm{~mL}$ SonoVue ${ }^{\mathrm{TM}} /$ Lumason $^{\mathrm{TM}}$ in the case of low-frequency transducers $[116,117]$, and (b) 2.4 $4.8 \mathrm{~mL}$ in the case of high-frequency transducers [116]. The firstpass of the small bowel enhancement is generally monitored $5 \mathrm{sec}$ after UCA injection and the maximum enhancement of the bowel wall is visualized after approximately $12-20 \mathrm{sec}$. Serial static images and multi-frame cine-clips during breath-holding are acquired and are available for post processing quantitative analysis, which includes evaluation of the following parameters in an operatordefined Region of Interest (ROI): percentage of maximal enhancement, time to peak, and area under the curve. These parameters were shown to have good correlation with endoscopy and histology grading.

\section{Level of Evidence}

There are no dedicated CEUS studies for the evaluation of IBD in children. Among several published studies, five included mixed population comprised of children older than 16 years of age and adults [116-120]. All of these studies demonstrated the effectiveness of CEUS in evaluation of IBD inflammatory activity and a strong correlation with the histological indices. A single case study regarding CEUS in epiploic appendagitis in child differentiation of phlegmonous infiltration from abscess formation appears to be a useful indication [121].

\section{Position Comment}

CEUS can be used as an alternative imaging modality for the follow up of children with known IBD to differentiate between active and quiescent disease and to evaluate the outcome of therapeutic strategies.

\section{Intra-cavity}

\section{Background}

Intra-cavitary and extravascular administration of UCA is an expanding off-label application, with numerous reported cases, but no prospective studies documented [7]. Although no specific recommendations have been issued, its use has been advocated where conventional techniques have either failed to reach a diagnosis or, importantly, are deemed to carry a higher risk (e. g. ionising radiation on sensitive organs). This is of particular importance in children, where efforts to find alternative imaging solutions to techniques involving ionizing radiation are paramount.

\section{Technique}

No standard doses are recommended with the reported range from $0.1 \mathrm{~mL}$ to $1 \mathrm{~mL}$ of SonoVue $\mathrm{TM}^{\mathrm{TM}} /$ Lumason $^{\mathrm{TM}}$ diluted in $0.9 \%$ nor- 
mal saline, depending on the type of cavity (physiological or not) and the aim of the study. To demonstrate a possible communication or fistulous track between two cavities a higher dose of $1 \mathrm{~mL}$ or $2 \mathrm{~mL}$ will be needed, whereas to delineate a pathological cavity (e. g. abscess), only a few drops are recommended to avoid artefacts and obscuration of the far field [122].

Level of Evidence

There is currently no literature focusing on intra-cavitary use of CEUS in children. A few applications of intra-cavitary CEUS in adults that can be applied to paediatric patients have been described. Trans-catheter use to evaluate the anatomy of the biliary tract and to detect obstruction or biliary leakage following T-tube removal has diagnostic accuracy comparable to percutaneous trans-hepatic cholangiography [122-126]. Trans-catheter CEUS in non-physiological cavities can allow identification of complications related to insertion of drainage tubes (such as dislocation or obstruction), and also give a quantitative measure of the volume of fluid present in a collection [127]. This technique may be uniquely useful in the nephrostomy tube or pleural space empyema where the visualization of the inter-costal drainage tube may be difficult. In the latter, trans-catheter CEUS could rapidly resolve this issue, even in a non-cooperating child, and direct management with fibrinolysis. Likewise, the injection of dilute UCA may guide adequate positioning of the tip of the catheter when managing a multi-loculated intra-abdominal or pelvic abscess.

\section{Position Comment}

The potential use of trans-catheter injection of UCA has been demonstrated in adults with possible uses in the child needing exploration, with the most likely use in the assessment of the pleural space in the presence of an empyema.

\section{Vascular applications: Neurosurgical and tumour re- sponse to antiangiogenic therapy}

\section{Background}

Although the use of CEUS has been established in the vascular field for carotid, abdominal aorta and cerebral vessels in the adult population, there is a limited role in children. One area that vascular application may be useful is in an intraoperative setting in neurosurgical intervention for the evaluation of brain lesions [128130]. There is increasing evidence that CEUS can allow for evaluation of the enhancement pattern of the tumour compared to the adjacent normal parenchyma, improved delineation of the tumor borders, visualization of the afferent, efferent or intra-lesional vessels, differentiation between viable tissue and areas of cystic degeneration or tumor necrosis and potentially identification of residual tumor. Quantification methods looking at the vascularity of a tumour, based on the time-intensity curves is useful to monitor response to antiangiogenic therapy in malignancy [131] and this has been applied to tumour response in children [132].

\section{Technique}

Initially, the lesion is visualized during B-mode US imaging, along with the healthy brain tissue. The US transducer is positioned over the lesion and after a bolus UCA injection, a digital cine clip of the lesion is recorded for up to $2-5$ min to allow for offsite evaluations. The most commonly reported SonoVue ${ }^{\mathrm{TM}} /$ Lumason $^{\mathrm{TM}}$ dose is $2.4 \mathrm{~mL}$ [128-130]. Qualitative analysis is performed for comparison of the enhancement pattern of the tumour compared to the adjacent normal brain tissue. In the tumour response patients, a bolus technique with the transducer placed over a region of interest, with subsequent evaluation of various aspects of the wash-in and wash-out curves [132].

\section{Level of Evidence}

Mixed case series of adult patients have described a few paediatric cases using intraoperative CEUS in diagnostics of brain lesions. This includes an 11-year-old patient in whom intraoperative CEUS was effective to precisely localize the brain tumour and search for tumour tissue residual after the initial resection [129], and the usefulness of intraoperative CEUS examination was evaluated in a 13-year-old patient with arteriovenous malformations to discriminate between the afferent and efferent vessels of the lesion [130]. A cohort of 17 patients assessed for tumour vascularity, targeting lesions in various locations, including liver and pleura, successfully predicted time to progression in a cohort of children and adolescents with recurrent solid tumours treated with antiangiogenic therapy [132].

\section{Position Comment}

CEUS is a promising imaging tool that may yield significant improvement in the macro- and micro-vascular assessment in transcranial ultrasound imaging. Tumour response following chemotherapy using the vascular enhancement may be better suited to follow-up in children.

\section{Vesico-ureteral reflux (VUR)}

\section{Background}

Contrast-enhanced voiding urosonography is a well-established application of paediatric CEUS. The examination entails bladder catheterization and intravesical UCA administration under real time US imaging. The main indications are the detection and grading of VUR and urethral imaging in children. There are numerous studies comparing ceVUS with the ionizing radiation counterparts of VCUG and DMSA [31, 32, 34, 36-42]. Contrastenhanced voiding urosonography is a highly sensitive, alternative imaging modality for the evaluation of VUR in children and in many centers it has replaced the traditionally performed VCUG $[35,133]$. New US techniques aimed at further improvement of the diagnostic capabilities of ceVUS include real time three- and four-dimensional ceVUS, which enables the volumetric visualization of contrast within a refluxing pelvicalyceal system, potentially improving grading [29], whereas intraoperative ceVUS can be used during endoscopic treatment of vesicoureteral reflux in children for direct evaluation of the operative outcome [33].

\section{Technique}

Following bladder catheterization, UCA is administered intravesically and real time US imaging of the kidneys and retrovesical space is performed during subsequent cycles of bladder filling and voiding with the child in supine and/or prone positions. 
Regarding UCA administration into the bladder during ceVUS performance, two techniques have been developed, the one most commonly used entails direct UCA injection into a partially filled bladder [134]. The other method entails the administration of UCA into a saline bag and subsequent drip infusion of the solution via the catheter into the bladder [42]. The presence of echogenic microbubbles within the ureter, renal pelvis and calyces is indicative of VUR, graded in a similar manner to VCUG. At the end of the examination morphological and functional study of the urethra is performed during a dedicated voiding cycle, using transperineal or transabdominal scanning approach [39].

\section{Level of Evidence}

Numerous studies have demonstrated the high sensitivity of ceVUS for the detection and grading of VUR. From the time when second generations UCA became commercially available, 14 original studies have been conducted with the intravesical use of SonoVue ${ }^{\mathrm{TM}} /$ Lumason $^{\mathrm{TM}}$ for the diagnosis of VUR including 2087 children [29, $31-42,133]$. The majority of these studies are comparative studies entailing the consecutive performance of ceVUS and VCUG; in only two studies was ceVUS the only examination performed. The studies that compared csVUS and VCUG have demonstrated the superiority of ceVUS over VCUG in detecting higher grade VUR, hence of greater clinical significance. The largest study recruited 1010 children and was primarily devoted to the safety evaluation of the intravesical administration of SonoVue $^{\mathrm{TM}} /$ Lumason $^{\mathrm{TM}}$ [35]. In addition, it is possible to image the urethra and accurately depict urethral abnormalities with a good diagnostic correlation as with VCUG [133]. A European survey has shown that ceVUS is being widely performed and up to 2012 , a total of 4131 ceVUS examinations have been safely performed in 29 European centers [28].

\section{Position Comment}

Contrast-enhanced voiding urosonography has proven to be a safe and reliable imaging technique for detecting VUR and urethral abnormalities in children of both genders.

\section{Future Perspectives}

Contrast-enhanced ultrasound has a number of distinct and well known advantages over CT and MR imaging, particularly in children, highly important for the future perspectives of CEUS $[45,135]$. The uncertainty surrounding the long-term effects of gadolinium deposition in children is a concern will drive the use of CEUS in children [136]. In addition to licensed indications with a focus on the liver and Doppler enhancement, CEUS is safe and effective for examination of almost all organs in adults, as indicated by the EFSUMB guidelines [6, 7]. "Off-label" use (and its funding) is the challenge in paediatric practice because many drugs are not tested by randomized trials in children, which also means that they are not specifically licensed for use in children. The recent licensing of SonoVue ${ }^{\mathrm{TM}} /$ Lumason $^{\mathrm{TM}}$ for use in paediatric liver US in the United States is a welcome first step towards the acceptance of this technique in the imaging of children.
Interessenkonflikte

OH Gilja: Lecture fees: GE Healthcare, Takeda AS, Med AS. Annamaria Deganello: Lecture fees, Bracco. Doris Franke: Lecture fee from Pfizer, travel grant from Novo Nordisk.

\section{References}

[1] Meng H, Grosse-Wortmann L. Gadolinium in pediatric cardiovascular magnetic resonance: what we know and how we practice. J Cardio Vasc Mag Res 2012; 14: 56

[2] Brenner DJ, Elliston C, Hall EJ et al. Estimated risks of radiation-induced fatal cancer from pediatric CT. Am J Roentgenol 2001; 176: 289-296

[3] Brenner DJ, Hall EJ. Cancer risks from CT scans: now we have data, what next? Radiology 2012; 265: 330 - 331

[4] Pearce MS, Salotti JA, Little MP et al. Radiation exposure from CT scans in childhood and subsequent risk of leukaemia and brain tumours: a retrospective cohort study. Lancet 2012; 380: 499- 505

[5] Piscaglia F, Bolondi L. The safety of SonoVue in abdominal applications: retrospective analysis of 23188 investigations. Ultrasound in Med Biol 2006; 32: $1369-1375$

[6] Claudon M, Dietrich CF, Choi BI et al. Guidelines and good clinical practice recommendations for contrast enhanced ultrasound (CEUS) in the liver - update 2012. Ultraschall in Med 2013; 34: 11-29

[7] Piscaglia F, Nolsoe C, Dietrich CF et al. The EFSUMB guidelines and recommendations on the clinical practice of contrast enhanced ultrasound (CEUS): update 2011 on non-hepatic applications. Ultraschall in Med 2012; 32: $33-59$

[8] Sidhu PS, Choi BI, Bachmann-Nielsen M. The EFSUMB guidelines and recommendations on the clinical practice of contrast enhanced ultrasound (CEUS): a new dawn for the escalating use of this ubiquitous technique. Ultraschall in Med 2012; 32: 5-7

[9] Piskunowicz P, Kosiak W, Irga N. Why can't we use second generation ultrasound contrast agents for the examination of children? Ultraschall in Med 2011; 32: $83-86$

[10] Conroy S, Choonara I, Impiccaitore P et al. Survey of unlicensed and off label drug use in paediatric wards in European countries. BMJ 2000; 320: $79-82$

[11] Prandstetter $C$, Tamesberger M, Wagner O et al. Verschreibepraxis von Arzneimitteln bei Fröh- und Neugeborenen auf einer Âsterreichischen neonatologischen Intensivstation. Klin Padiatr 2009; 221: 312 - 317

[12] Pandolfini C, Bonati M. A literature review on off label drug use in children. Eur J Pediatr 2005; 164: 552 - 558

[13] Sellars ME, Deganello A, Sidhu PS. Paediatric contrast-enhanced ultrasound (CEUS); a technique that requires co-operation for rapid implementation into clinical practice. Ultraschall in Med 2014; 35: 203 - 206

[14] Darge K, Troeger ], Duetting T et al. Reflux in young patients: comparison of voiding US of the bladder and retrovesical space with echo enhancement versus voiding cystourethrography for diagnosis. Radiology 1999; 210: $201-207$

[15] Darge K, Papadopoulu F, Ntoulia A et al. Safety of contrast-enhanced ultrasound in children for non-cardiac applications: a review by the Society for Pediatric Radiology (SPR) and the International Contrast Ultrasound Society (ICUS). Pediatr Radiol 2013; 43: 1063-1073

[16] Rosado E, Riccabona M. Off-label use of ultrasound contrast agents for intravenous applications in children. Analysis of the existing literature. J Ultrasound Med 2016; 35: e21 - e30

[17] Coleman JL, Navid F, Furman WL et al. Safety of ultrasound contrast agents in the pediatric oncologic population: a single-institution experience. Am J Roentgenol 2014; 202: 966 -970 
[18] Valentino M, Serra C, Zironi G et al. Blunt Abdominal Trauma: Emergency Contrast-Enhanced Sonography for Detection of Solid Organ Injuries. Radiology 2006; 186: 1361 - 1367

[19] Menichini G, Sessa B, Trinci M et al. Accuracy of contrast-enhanced ultrasound (CEUS) in the identification and characterization of traumatic soild organ lesions in children: a retrospective comparison with baseline US and CEMDCT. Radiol Med 2015; 120: 989-1001

[20] McCarville MB, Kaste SC, Hoffer FA et al. Contrast-enhanced sonography of malignant pediatric abdominal and pelvic solid tumors: preliminary safety and feasibility data. Pediatr Radiol 2012; 42: 824-833

[21] Piskunowicz P, Kosiak W, Batko T et al. Safety of intravenous application of second generation ultrasound contrast agent in children: prospective analysis. Ultrasound Med Biol 2015; 41: 1095 - 1099

[22] Food \& Drug Administration. MARCH 2016 - APPROVED DRUG PRODUCT LIST. 2016 http://www.fda.gov/downloads/drugs/developmentapprovalprocess/ucm071120.pdf

[23] Bracco. Lumason Prescribing Information. 2016 http://imaging.bracco. com/sites/braccoimaging.com/files/technica_sheet_pdf/US-20160330LUMASON-PI_0.pdf

[24] Prince MR, Zhang $\mathrm{H}$, Zou $\mathrm{Z}$ et al. Incidence of immediate gadolinium contrast media reactions. Am J Roentgenol 2011; 196: W138-W143

[25] Wang CL, Cohan RH, Ellis JH et al. Frequency, outcome, and appropriatness of treatment of nonionic iodinated contrast media reactions. Am J Roentgenol 2008; 191: 409-415

[26] McMahon C], Ayres NA, Bezols LI et al. Safety and efficacy of intravenous contrast imaging in pediatric echocardiography. Pediatr Cardiol 2005; 26: $413-417$

[27] Stenzel M. Intravenous contrast-enhanced sonography in children and adolescents - a single center experience. J Ultrason 2013; 13: 133 - 144

[28] Riccabona M. Application of a second-generation US contrast agent in infants and children - a European questionnaire-based survey. Pediatr Radiol 2012; 42: 1471 - 1480

[29] Wozniak MM, Wieczorek AP, Pawelec A et al. Two-dimensional (2D), three-dimensional static (3D) and real-time (4D) contrast enhanced voiding urosonography (ceVUS) versus voiding cystourethrography (VCUG) in children with vesicoureteral reflux. Eur ] Radiol 2016; 85: $1238-1245$

[30] Veldhoen S, Sauer A, Gassenmaier T et al. Contrast-enhanced voiding urosonography phantom study: intravenous iodinated and gadoliniumbased contrast agents may cause false-negative results in assessment of vesicoureteral reflux in children. Pediatr Radiol 2015; 45: 862 - 871

[31] Faizah MZ, Hamzaini AH, Kanaheswari Y et al. Contrast-enhanced voiding urosonography (ce-VUS) as a radiation free technique in the diagnosis of vesicoureteric reflux. Med J Malaysia 2015; 70: 269-272

[32] Babu R, Gopinath V, Sai V. Voiding urosonography: Contrast-enhanced ultrasound cystography to diagnose vesico-ureteric reflux: A pilot study. J Indian Assoc Pediatr Surg 2015; 20: 40 -41

[33] Wozniak MM, Osemlak P, Pawelec A et al. Intraoperative contrast-enhanced urosonography during endoscopic treatment of vesicoureteral reflux in children. Pediatr Radiol 2014; 44: $1093-1100$

[34] Wong LS, Tse KS, Fan TW et al. Voiding urosonography with secondgeneration ultrasound contrast versus micturating cystourethrography in the diagnosis of vesicoureteric reflux. Eur J Pediatr 2014; 173: 1095 1101

[35] Papadopoulou F, Ntoulia A, Siomou E et al. Contrast-enhanced voiding urosonography with intravesical administration of a second-generation ultrasound contrast agent for diagnosis of vesicoureteral reflux: prospective evaluation of contrast safety in 1010 children. Pediatr Radiol 2014; 44: 719-728

[36] Kljuievíek D, Battelino N, Tomazìc $M$ et al. A comparison of echo-enhanced voiding urosonography with $X$-ray voiding cystourethrography in the first year of life. Acta Paediatrica 2012; 101: e235 - e239
[37] Kis E, Nyitrai A, Varkonyi I et al. Voiding urosonography with secondgeneration contrast agent versus voiding cystourethrography. Pediatr Nephrol 2010; 25: 2289-2293

[38] Papadopoulou F, Anthopoulou A, Siomou E et al. Harmonic voiding urosonography with a second-generation contrast agent for the diagnosis of vesicoureteral reflux. Pediatr Radiol 2009; 39: 239-244

[39] Duran C, Valera A, Alguersuari A et al. Voiding urosonography: the study of the urethra is no longer a limitation of the technique. Pediatr Radiol 2009; 39: $124-131$

[40] Darge K, Moeller RT, Trusen A et al. Diagnosis of vesicoureteric reflux with low-dose contrast-enhanced harmonic ultrasound imaging. Pediatr Radiol 2005; 35: $73-78$

[41] Ascenti G, Zimbaro G, Mazziotti S et al. Harmonic US imaging of vesicoureteric reflux in children: usefulness of a second generation US contrast agent. Pediatr Radiol 2004; 34: 481 -487

[42] Fernaíndez-Ibieta M, Parrondo-Muiros C, Fernaíndez-Masaguer LC et al. Urosonografija miccional con contraste de segunda generacin como herramienta primaria en el estudio de la vija urinaria superior e inferior en pediatrija. Estudio Piloto. Actas Urolgicas Espaolas 2016; 40: 183-189

[43] Miller DL, Averkiou MA, Brayman AA et al. Bioeffects Considerations for Diagnostic Ultrasound Contrast Agents. J Ultrasound Med 2008; 27 : $611-632$

[44] Piskunowicz P, Kosiak W, Batko T. Intravenous application of secondgeneration ultrasound contrast agents in children: a review of the literature. Ultraschall in Med 2012; 33: 135-140

[45] Jacob J, Deganello A, Sellars ME et al. Contrast Enhanced Ultrasound (CEUS) Characterization of Grey-scale Sonographic Indeterminate Focal Liver Lesions in Paediatric Practice. Ultraschall in Med 2013; 34: 529- 540

[46] Bonini G, Pezzotta G, Morzenti C et al. Contrast-enhanced ultrasound with SonoVue in the evaluation of postoperative complications in pediatric liver transplant recipients. J Ultrasound 2007; 10: 99-106

[47] Knieling F, Strobel D, Rompel O et al. Spectrum, Applicability and Diagnostic Capacity of Contrast-Enhanced Ultrasound in Pediatric Patients and Young Adults after Intravenous Application - A Retrospective Trial. Ultraschall in Med 2016; In press DOI: 10.1055/s-0042-108429

[48] Fernandez E, Perez R, Hernandez A et al. Factors and Mechanisms for Pharmacokinetic Differences between Pediatric Population and Adults. Pharmaceutics 2011; 3: $53-72$

[49] Gasparini C, Bertolotto M, Croce SL et al. Evaluation of liver parenchyma blood flow with contrast-enhanced US: preliminary results in healthy and cirrhotic patients. Acad Radiol 2003; 10: 869-876

[50] Zhang P, Zhou P, Tian SM et al. Diagnostic performance of contrast-enhanced sonography and acoustic radiation force impulse imaging in solid liver lesions. J Ultrasound Med 2014; 33: 205 - 214

[51] Rennert ], Dornia C, Georgieva M et al. Identification of early complications following liver transplantation using contrast enhanced ultrasound (CEUS). First results. J Gastrointestin Liver Dis 2012; 21: 407 -412

[52] Pei XQ, Liu LZ, Liu M et al. Contrast-enhanced ultrasonography of hepatocellular carcinoma: correlation between quantitative parameters and histological grading. Bri J Radiol 2012; 85: e740 - e747

[53] Rennert ], Georgieva M, Schreyer AG et al. Image fusion of contrast enhanced ultrasound (CEUS) with computed tomography (CT) or magnetic resonance imaging (MRI) using volume navigation for detection, characterization and planning of therapeutic interventions of liver tumors. Clin Hemorheol Microcirc 2011; 49: 67 - 81

[54] Seitz K, Ströbel D, Bernatik T et al. Contrast-Enhanced Ultrasound (CEUS) for the Characterization of Focal Liver Lesions Prospective Comparison in Clinical Practice: CEUS vs. CT (DEGUM Multicenter Trial). Ultraschall in Med 2009; 30: 383-389

[55] Wang ZL, Tang J, Weskott HP et al. Undetermined focal liver lesions on gray-scale ultrasound in patients with fatty liver: Characterization with contrast-enhanced ultrasound. J Gastroenterol Hepatol 2008; 23: $1511-1519$ 
[56] Ungermann L, Elias P, Zizka J et al. Focal nodular hyperplasia: Spokewheel arterial pattern and other signs on dynamic contrast-enhanced ultrasonography. Eur J Radiol 2007; 63: 290-294

[57] Soye JA, Mullan CP, Porter S et al. The use of contrast-enhanced ultrasound in the characterisation of focal liver lesions. Ulster Med J 2007; 76: 22 - 25

[58] Wu W, Chen MH, Yin SS et al. The Role of Contrast-Enhanced Sonography of Focal Liver Lesions Before Percutaneous Biopsy. Am J Roentgenol 2006; 187: $752-761$

[59] Seitz K, Bernatik T, Strobel D et al. Contrast-enhanced ultrasound (CEUS) for the characterization of focal liver lesions in clinical practice (DEGUM Multicenter Trial): CEUS vs. MRI - a prospective comparison in 269 patients. Ultraschall in Med 2010; 31: 492-499

[60] Stenzel M, Mentzel HJ. Ultrasound elastography and contrast-enhanced ultrasound in infants, children and adolescents. Euro J Radiol 2014; 83: $1560-1569$

[61] Schreiber-Dietrich D, Dietrich CF. Contrast enhanced ultrasound (CEUS) and off-label use (in children). Ultraschall in Med 2012; 33: 295-296

[62] Riccabona M, Avni FE, Damasio MB et al. ESPR Uroradiology Task Force and ESUR Paediatric Working GroupGÇölmaging recommendations in paediatric uroradiology, Part V: childhood cystic kidney disease, childhood renal transplantation and contrast-enhanced ultrasonography in children. Pediatr Radiol 2012; 42: 1275-1283

[63] McCarville MB. Contrast-enhanced sonography in pediatrics. Pediatr Radiol 2011; 41: S238-S242

[64] Parker JM, Weller MW, Feinstein LM et al. Safety of Ultrasound Contrast Agents in Patients With Known or Suspected Cardiac Shunts. Am J Cardiol 2013; 112: 1039-1045

[65] Harvey C], Alsafi A, Kuzmich S et al. Role of US contrast agents in the assessment of indeterminate solid and cystic lesions in native and transplant kidneys. Radiographics 2015; 35: 1419-1430

[66] Riccabona M, Vivier PH, Ntoulia A et al. ESPR uroradiology task force imaging recommendations in paediatric uroradiology, part VII: standardised terminology, impact of existing recommendations, and update on contrast-enhanced ultrasound of the paediatric urogenital tract. Pediatr Radiol 2014; 44: 1478 - 1484

[67] Harkanyi Z. Potential applications of contrast-enhanced ultrasound in pediatric patients. Ultrasound Clin North Am 2013; 8: 403-422

[68] Yusuf GT, Sellars ME, Huang DY et al. Cortical Necrosis Secondary to Trauma in a Child: Contrast-enhanced ultrasound comparable to Magnetic Resonance Imaging. Pediatr Radiol 2014; 44: 484-487

[69] Weskott HP. Kidney and collective system. In: Weskott HP, editor. Contrast enhance ultrasound. 2nd ed Bremen: Uni-Med Verla AG; 2013: 152-189

[70] Pinto F, Valentino M, Romanini L et al. The role of CEUS in the assessment of haemodynamically stable patients with blunt abdominal trauma. Radiol Med 2014; 120: 3-11

[71] Durkin N, Deganello A, Sellars ME et al. Post-traumatic liver and spleen pseudoaneurysms in children: diagnosis, management and follow-up screening using contrast enhanced ultrasound (CEUS). J Pediat Surg 2016; 51: 289-292

[72] Harvey C], Sidhu PS, Bachmann-Nielsen M. Contrast-enhanced ultrasound in renal transplants: applications and future directions. Ultraschall in Med 2013; 34: 319-321

[73] Valentino M, Serra C, Pavlica P et al. Blunt Abdominal Trauma: Diagnostic Performance of Contrast-enhanced US in Children: Initial Experience. Radiology 2008; 246: 903-909

[74] Thorelius L. Emergency real-time contrast-enhanced ultrasonography for detection of solid organ injuries. Eur Radiol 2007; 17: F107-F111

[75] Oldenburg A, Hohmann J, Skork J et al. Imaging of pediatric splenic injury with contrast-enhanced ultrasonography. Pediatr Radiol 2004; 34: $351-354$

[76] Catalano O, Aiani L, Barozzi L et al. CEUS in abdominal trauma: multicenter study. Abdominal Imaging 2009; 34: 225-234
[77] Valentino M, Galloni SS, Rimondi MR et al. Contrast-enhanced ultrasound in non-operative management of pancreatic injury in childhood. Pediatr Radiol 2006; 36: 558-560

[78] Miele V, Piccolo CL, Sessa B et al. Comparison between MRI and CEUS in the follow-up of patients with blunt abdominal trauma managed conservatively. Radiol Med 2015; 121: 27-37

[79] Sessa B, Trinci M, lanniello S et al. Blunt abdominal trauma: role of contrast-enhanced ultrasound (CEUS) in the detection and staging of abdominal traumatic lesions compared to US and CE-MDCT. Radiol Med 2014; 120: $180-189$

[80] Manetta R, Pistoia ML, Bultrini C et al. Ultrasound enhanced with sulphur-hexafluoride-filled microbubbles agent (SonoVue) in the follow-up of mild liver and spleen trauma. Radiol Med 2009; 114: 771 - 779

[81] Catalano O, Sandomenico F, Raso MM et al. Real-time, contrast-enhanced sonography: a new tool for detecting active bleeding. J Trauma 2005; 59: $933-939$

[82] Catalano O, Lobianco R, Sandomenico F et al. Real-time, contrast-enhanced sonographic imaging in emergency radiology. Radiol Med 2004; 108: $454-469$

[83] Catalano O, Lobianco R, Sandomenico F et al. Real-time contrast enhanced ultrasound of the spleen: examination technique and preliminary clinical experience. Radiol Med 2003; 106: 338-356

[84] Miele V, Buffa V, Stasolla A et al. Contrast enhanced ultrasound with second generation contrast agent in traumatic liver lesions. Radiol Med 2004; 108: 82-91

[85] Berry JD, Sidhu PS. Microbubble contrast-enhanced ultrasound in liver transplantation. Eur Radiol 2004; 14: P96-P103

[86] Sidhu PS, Marshall MM, Ryan SM et al. Clinical use of Levovist, an ultrasound contrast agent, in the imaging of liver transplantation: assessment of the pre and post transplant patient. Eur Radiol 2000; 10: 1114-1126

[87] Sidhu PS, Ellis SM, Karani JB et al. Hepatic artery stenosis following liver transplantation: significance of the tardus parvus waveform and the role of microbubble contrast media in the detection of a focal stenosis. Clin Radiol 2002; 57: 789-799

[88] Sidhu PS, Shaw AS, Ellis SM et al. Microbubble ultrasound contrast in the assessment of hepatic artery patency following liver transplantation: role in reducing frequency of hepatic artery arteriography. Eur Radiol 2004; $14: 21-30$

[89] Kersting S, Ludwig S, Ehehalt F et al. Contrast-Enhanced Ultrasonography in Pancreas Transplantation. Transplantation 2013; 95: 209-214

[90] Kay DH, Mazonakis M, Geddes C et al. Ultrasonic microbubble contrast agents and the transplant kidney. Clin Radiol 2009; 64: 1081-1087

[91] Fernandez CP, Ripolles T, Martinez M] et al. Diagnosis of acute cortical necrosis in renal transplantation by contrast-enhanced ultrasound: a preliminary experience. Ultraschall in Med 2013; 34: 338- 342

[92] Stenberg B, Talbot D, Khurram M et al. A new technique for assessing renal transplant perfusion preoperatively using contrast-enhanced ultrasound (CEUS) and three-dimensional ultrasound (3DUS) - a porcine modelpilot study. Ultraschall in Med 2011; 32: E8-E13

[93] Stenberg B, Chandler C, Wyrley-Birch H et al. Post-Operative 3-Dimensional Contrast-Enhanced Ultrasound (CEUS) Versus Tc99m-DTPA in the Detection of Post-Surgical Perfusion Defects in Kidney Transplants GÇô Preliminary Findings. Ultraschall in Med 2014; 35: 273-278

[94] Rennert ], Farkas S, Georgieva M et al. Identification of early complications following pancreas and renal transplantation using contrast enhanced ultrasound (CEUS) - first results. Clin Hemorheol Microcirc 2014; 58: $343-352$

[95] Benozzi L, Cappelli G, Granito M et al. Contrast-Enhanced Sonography in Early Kidney Graft Dysfunction. Transplant Proc 2009; 41: 1214-1215

[96] Masetti R, Zama D, Gasperini P et al. Focal nodular hyperplasia of the liver in children after hematopoietic stem cell transplantation. Pediatr Transplantation 2013; 17: 479-486 
[97] Pschierer K, Grothues D, Rennert J et al. Evaluation of the diagnostic accuracy of CEUS in children with benign and malignant liver lesions and portal vein anomalies. Clin Hemorheol Microcirc 2015; 61: 333-345

[98] Geis S, Prantl L, Dolderer J et al. Postoperative Monitoring of Local and Free Flaps with Contrast-Enhanced Ultrasound (CEUS) Analysis of 112 Patients. Ultraschall in Med 2013; 34: 550 - 558

[99] Schreyer AG, Landfried K, Zorger $\mathrm{N}$ et al. Transmural penetration of intravenously applied microbubbles during contrast-enhanced ultrasound as a new diagnostic feature in patients with GVHD of the bowel. Bone Marrow Transplant 2011; 46: 1006 - 1011

[100] Görg C, Bert T, Kring R et al. Transcutaneous contrast enhanced sonography of the chest for evaluation of pleural based pulmonary lesions: experience in 137 patients. Ultraschall in Med 2006; 27: 437-444

[101] Görg C, Kring R, Bert T. Transcutaneous Contrast-Enhanced Sonography of Peripheral Lung Lesions. Am J Roentgenol 2006; 187: W420 - W429

[102] Görg C, Bert T, Kring R. Contrast-Enhanced Sonography of the Lung for Differential Diagnosis of Atelectasis. J Ultrasound Med 2006; 25: 35- 39

[103] Görg C, Bert T, Gorg K. Contrast-Enhanced Sonography for Differential Diagnosis of Pleurisy and Focal Pleural Lesions of Unknown Cause. Chest 2005; 128: $3894-3899$

[104] Linde HN, Holland A, Greene BH et al. Kontrastunterstzte Sonografie (CEUS) bei Pneumonie: Darstellungsmuster und prognostische Bedeutung eine retrospektive Studie bei 50 Patienten. Ultraschall in Med 2012; 33: $146-151$

[105] Di Vece F, Tombesi P, Ermili F et al. Contrast-enhanced ultrasound (CEUS) and CEUS-guided biopsy in the diagnosis of lung abscess in a patient with achalasia: Case report. Interv Med Appl Sci 2013; 5: 31 - 33

[106] Sartori S, Nielsen I, Trevisani L et al. Contrast-Enhanced Sonography as Guidance for Transthoracic Biopsy of a Peripheral Lung Lesion With Large Necrotic Areas. J Ultrasound Med 2004; 23: 133-136

[107] Görg C. Transcutaneous contrast-enhanced sonography of pleuralbased pulmonary lesions. Eur J Radiol 2007; 64: 213-221

[108] Cokkinos DD, Antypa E, Stefanidis K et al. Contrast-enhanced ultrasound for imaging blunt abdominal trauma - indications, description of the technique and imaging review. Ultraschall in Med 2012; 33: 60-67

[109] Hershkovitz Y, Zoarets I, Stepansky A et al. Computed tomography is not justified in every pediatric blunt trauma patient with a suspicious mechanism of injury. Am J Emerg Med 2014; 32: 697-699

[110] Benedetti E, Proietti A, Miccoli P et al. Contrast-enhanced ultrasonography in nodular splenomegaly associated with type B Niemann. Pick disease: an atypical hemangioma enhancement pattern. J Ultrasound 2009; 12: 85-92

[111] Friedrich-Rust M, Schneider G, Bohle RM et al. Contrast-Enhanced Sonography of Adrenal Masses: Differentiation of Adenomas and Nonadenomatous Lesions. Am J Roentgenol 2008; 191: 1852-1860

[112] Friedrich-Rust M, Glasemann T, Polta A et al. Differentiation between benign and malignant adrenal mass using contrast-enhanced ultrasound. Ultraschall in Med 2011; 32: 460-471

[113] Dietrich CF, Ignee A, Barreiros AP et al. Contrast-enhanced ultrasound for imaging of adrenal masses. Ultraschall in Med 2010; 31: 163-168

[114] Al Bunni F, Deganello A, Sellars ME et al. Contrast-enhanced ultrasound (CEUS) appearances of an adrenal phaeochromocytoma in a child with Von Hippel-Lindau disease. J Ultrasound 2014; 17: 307-311

[115] Schreiber-Dietrich D, Buchhorn R, Dietrich CF. Blickdiagnose nebennierentumor (Phachromozytom). Padiat Prax 2014; 83: 239-248

[116] Quaia E, Cabibbo B, Paoli L et al. The value of time-intensity curves obtained after microbubble contrast agent injection to discriminate responders from non-responders to anti-inflammatory medication among patients with Crohns disease. Eur Radiol 2013; 23: 1650 - 1659

[117] Paredes JMA, Ripolls T, Corts $X$ et al. Contrast-enhanced ultrasonography: Usefulness in the assessment of postoperative recurrence of Crohn's disease. J Crohn's and Colitis 2013; 7: 192-201
[118] Quaia E, De Paoli L, Stocca T et al. The Value of Small Bowel Wall Contrast Enhancement After Sulfur Hexafluoride-Filled Microbubble Injection to Differentiate Inflammatory from Fibrotic Strictures in Patients with Crohn's Disease. Ultrasound Medicine Biol 2012; 38: 1324-1332

[119] Girlich C, Jung EM, Huber E et al. Comparison between Preoperative Quantitative Assessment of Bowel Wall Vascularization by ContrastEnhanced Ultrasound and Operative Macroscopic Findings and Results of Histopathological Scoring in Crohns Disease. Ultraschall in Med 2011; 32: $154-159$

[120] Migaleddu V, Scanu AM, Quaia E et al. Contrast-Enhanced Ultrasonographic Evaluation of Inflammatory Activity in Crohn's Disease. Gastroenterol 2009; 137: 43-52

[121] Gorg C, Egbring J, Bert T. Contrast enhanced ultrasound of epiploic appendagitis. Ultraschall in Med 2009; 30: $163-167$

[122] Ignee A, Cui X, Schuessler G et al. Percutaneous transhepatic cholangiography and drainage using extravascular contrast enhanced ultrasound. Z Gastroenterol 2015; 53: 385-390

[123] Sparchez Z, Radu P, Sparchez M et al. Intracavitary applications of ultrasound contrast agents in hepatogastroenterology. J Gastrointestin Liver Dis 2013; 22: 349-353

[124] Luyao Z, Xiaoyan X, Huixiong $X$ et al. Percutaneous ultrasound-guided cholangiography using microbubbles to evaluate the dilated biliary tract: intial experience. Eur Radiol 2012; 22: $371-378$

[125] Xu E], Zheng RQ, Su ZZ et al. Intra-biliary contrast-enhanced ultrasound for evaluating biliary obstruction during percutaneous transhepatic biliary drainage: a preliminary study. Eur J Radiol 2012; 81: $3846-3850$

[126] Daneshi M, Rajayogeswaran B, Peddu P et al. Demonstration of an ocult biliary-arterial fistula using percutaneous contrast-enhanced ultrasound cholangiography in a transplanted liver. J Clin Ultrasound 2014; 42: $108-111$

[127] Heinzmann A, Muller T, Leitlein J et al. Endocavity contrast enhanced ultrasound (CEUS) - work in progress. Ultraschall in Med 2012; 33: $76-84$

[128] Prada F, Perin A, Martegani A et al. Intraoperative contrast-enhanced ultrasound for brain tumor surgery. Neurosurg 2014; 74: 542-552

[129] He W, Jiang XQ, Wang $S$ et al. Intraoperative contrast-enhanced ultrasound for brain tumors. Clin Imaging 2008; 32: 419-424

[130] Wang $Y$, Wang $Y$, Wang $Y$ et al. Intraoperative real-time contrast-enhanced ultrasound angiography: a new adjunct in the surgical treatment of arteriovenous malformations. J Neurosurg 2007; 107: 959964

[131] Lassau N, Chebil M, Chami L et al. Dynamic contrast-enhanced ultrasonography (DCE-US): a new tool for the early evaluation of antiangiogenic treatment. Target Oncol 2010; 5: 53-58

[132] McCarville MB, Coleman JL, Guo J et al. Use of Quantitative Dynamic Contrast-Enhanced Ultrasound to Assess Response to Antiangiogenic Therapy in Children and Adolescents With Solid Malignancies: A Pilot Study. Am J Roentgenol 2016; 206: 933-939

[133] Duran C, Riego J, Riera L et al. Voiding urosonography including urethrosonography: high-quality examinations with an optimised procedure using a second-generation US contrast agent. Pediatric Radiology 2012; 42: 660-667

[134] Darge K. Voiding urosonography with US contrast agents for the diagnosis of vesicureteric reflux in children. I. Procedure. Pediatr Radiol 2008; 38: $40-53$

[135] Schreiber-Dietrich DG, Cui XW, Piscaglia F et al. Contrast Enhanced Ultrasound in Pediatric Patients: A real Challenge. Z Gastroenterol 2014; 52: $1178-1184$

[136] Kanal E, Tweedle MF. Residual or Retained Gadolinium: Practical Implications for Radiologists and Our Patients. Radiology 2015; 275: 630634 